\title{
Correction: Person-Generated Health Data in Women's Health: Protocol for a Scoping Review
}

\author{
Jalisa Lynn Karim ${ }^{1,2}$; Aline Talhouk ${ }^{2}$, PhD
}

${ }^{1}$ Department of Statistics and Actuarial Science, University of Waterloo, Waterloo, ON, Canada

${ }^{2}$ Department of Obstetrics and Gynecology, University of British Columbia, Vancouver, BC, Canada

\section{Corresponding Author:}

Aline Talhouk, PhD

Department of Obstetrics and Gynecology

University of British Columbia

593-828 West 10th Ave

Vancouver, BC, V5Z 1M9

Canada

Phone: 16048754111

Email: a.talhouk@ubc.ca

\section{Related Article:}

Correction of: https://www.researchprotocols.org/2021/5/e26110

(JMIR Res Protoc 2021;10(10):e34211) doi: 10.2196/34211

In "Person-Generated Health Data in Women's Health: Protocol for a Scoping Review" (JMIR Res Protoc 2021;10(5):e26110), one error was noted.

The phone number for the Corresponding Author in the originally published manuscript has been removed and replaced by the phone number "1 6048754111 ."
The correction will appear in the online version of the paper on the JMIR Publications website on October 18, 2021, together with the publication of this correction notice. Because this was made after submission to PubMed, PubMed Central, and other full-text repositories, the corrected article has also been resubmitted to those repositories.

This is a non-peer-reviewed article. Submitted 11.10.21; accepted 11.10.21; published 18.10.21.

Please cite as:

Karim JL, Talhouk A

Correction: Person-Generated Health Data in Women's Health: Protocol for a Scoping Review

JMIR Res Protoc 2021;10(10):e34211

URL: https://www.researchprotocols.org/2021/10/e34211

doi: $\underline{10.2196 / 34211}$

PMID:

CJalisa Lynn Karim, Aline Talhouk. Originally published in JMIR Research Protocols (https://www.researchprotocols.org), 18.10.2021. This is an open-access article distributed under the terms of the Creative Commons Attribution License (https://creativecommons.org/licenses/by/4.0/), which permits unrestricted use, distribution, and reproduction in any medium, provided the original work, first published in JMIR Research Protocols, is properly cited. The complete bibliographic information, a link to the original publication on https://www.researchprotocols.org, as well as this copyright and license information must be included. 